\title{
Feminization and the collapse of haplodiploidy in an asexual parasitoid wasp harboring the bacterial symbiont Cardinium
}

\author{
M Giorgini ${ }^{1}$, MM Monti ${ }^{1}$, E Caprio ${ }^{2}, \mathrm{R}_{\text {Stouthamer }}{ }^{3}$ and MS Hunter ${ }^{4}$ \\ ${ }^{1}$ Istituto per la Protezione delle Piante, Consiglio Nazionale delle Ricerche, Portici, Napoli, Italy; ${ }^{2}$ Dipartimento di Entomologia \\ e Zoologia agraria 'Filippo Silvestri', Università di Napoli 'Federico II', Portici, Napoli, Italy; ' ${ }^{2}$ epartment of Entomology, \\ University of California, Riverside, CA, USA and ${ }^{4}$ Department of Entomology, University of Arizona, Tucson, AZ, USA
}

\begin{abstract}
Cardinium is a bacterial symbiont infecting many species of arthropods, and is associated with manipulation of host reproduction. Cardinium is the causal agent of asexual reproduction, or thelytoky, in the chalcidoid parasitoid wasp Encarsia hispida. Feeding antibiotics to the infected adult females results in uninfected male offspring. Here, we show that these males are diploid. Diploid males are extremely unusual in the large hymenopteran superfamily Chalcidoidea, and, to our knowledge, have never before been associated with symbiont infection in this group. These
\end{abstract}

findings indicate that at least in E. hispida, diploidy restoration is a necessary condition but not sufficient to elicit female development. Cardinium is required to feminize diploid male embryos and thus must interact with elements of the host sex determination system. In addition, our data suggest that Cardinium is necessary for the fertility of E. hispida; antibiotic curing of Cardinium reduces offspring production of adult females.

Heredity (2009) 102, 365-371; doi:10.1038/hdy.2008.135; published online 4 February 2009

Keywords: diploid males; feminization; Hymenoptera; parthenogenesis; sex determination; Wolbachia

\section{Introduction}

Cardinium are bacteria in the Bacteroidetes that are intracellular, inherited symbionts of arthropods (Zchori-Fein et al., 2004). Cardinium has been detected in $6-7 \%$ of arthropods screened, and has been found in the Hymenoptera, Hemiptera and Acari (Weeks et al., 2003; Zchori-Fein and Perlman, 2004). Recently, a high incidence $(22 \%)$ has been detected in spiders (Araneae) (Duron et al., 2008). Like Wolbachia, in the $\alpha$-Proteobacteria, Cardinium may cause manipulation of host reproduction in ways that increase its frequency within a host population, including feminization (genotypic males develop as functional phenotypic females) (Weeks et al., 2001), cytoplasmic incompatibility (Hunter et al., 2003; Gotoh et al., 2007) and thelytokous parthenogenesis (females produce only daughters from unfertilized eggs) (Zchori-Fein et al., 2001, 2004; Provencher et al., 2005; Groot and Breeuwer, 2006; Matalon et al., 2007). Cardinium also increases the fecundity of a mite host (Weeks and Stouthamer, 2004).

Here, we study an asexual parasitic wasp, Encarsia hispida, which is infected by Cardinium (Zchori-Fein et al., 2004). Single (Cardinium or Wolbachia) and multiple

Correspondence: Dr M Giorgini, Istituto per la Protezione delle Piante, Consiglio Nazionale delle Ricerche, via Università 133, Portici, Napoli 80055, Italy.

E-mail: giorgini@ipp.cnr.it

Received 25 June 2008; revised 6 October 2008; accepted 3 December 2008; published online 4 February 2009
(Cardinium plus Wolbachia) bacterial infections are frequent in the genus Encarsia (Hymenoptera: Chalcidoidea: Aphelinidae) (Perlman et al., 2006), a group of endoparasitoid wasps that attack mainly whiteflies or armoured scale insects (Heraty and Woolley, 2002). In this genus, bacterial symbionts are associated with cytoplasmic incompatibility, thelytokous parthenogenesis and a change of the wasp host selection behavior (Hunter and Zchori-Fein, 2006; Perlman et al., 2006; Kenyon and Hunter, 2007). Like other Hymenoptera, sexual Encarsia species reproduce by arrhenotokous parthenogenesis, that is, females develop from diploid, fertilized eggs, whereas males develop parthenogenetically from haploid, unfertilized eggs (Hunter and Woolley, 2001). Some species of Encarsia are asexual, that is, thelytokous parthenogens with rare or unknown males. All asexual species of Encarsia examined to date are infected by Cardinium, except for Encarsia formosa, where the causal agent of thelytoky is Wolbachia (van Meer et al., 1999; Zchori-Fein et al., 2001). The role of Cardinium in the induction of thelytoky has been confirmed only in E. hispida (ZchoriFein et al., 2004) but nothing is known about the mechanisms used by this symbiont to induce the production of all-female offspring.

Symbiotic microorganisms that manipulate host reproduction can promote evolutionary changes in their hosts by interacting with fundamental biological processes, such as sex determination, sexual differentiation and the cell cycle (Werren and O'Neill, 1997; Charlat et al., 2003). The arthropod sex determination system is the target of feminizing and male-killing microorganisms 
and the genetic conflict occurring between microbial genes and host nuclear genes can be an important force that drives the diversification of sex determination (Werren and Beukeboom, 1998; Caubet et al., 2000). Within infected host populations, microbial genes are selected to favor a female-biased host sex ratio, which increases the transmission of cytoplasmically inherited microorganisms, whereas host genes are selected to prevent the action of the symbionts and restore an unbiased sex ratio. As a consequence of this conflict, new host sex-determining genes can be selected. The bestknown example of such a conflict is in the female heterogametic isopod Armadillidium vulgare (Rigaud, 1997; Caubet et al., 2000). Also relevant to this study, symbionts have been implicated in possible evolutionary routes to haplodiploidy (Hamilton, 1993; Normark, 2004).

Here, we show that asexual reproduction of E. hispida depends ultimately on Cardinium-mediated feminization of genetic diploid males. In addition, Cardinium seems necessary for the fertility of infected females.

\section{Materials and methods}

\section{Study insect}

Encarsia hispida is a cosmopolitan parasitoid of whiteflies and contributes to biological control of economic pests such as the sweetpotato whitefly, Bemisia tabaci and the greenhouse whitefly, Trialeurodes vaporariorum (Polaszek et al., 2004). It is fixed for asexuality but male production can be induced by feeding infected adult females antibiotics (Hunter, 1999; Giorgini, 2001). We studied two populations of E. hispida, one collected in Portici, Napoli, Italy from B. tabaci, the other in San Diego, California, CA, USA from the giant whitefly Aleurodicus dugesii. They were reared in the laboratory at $25 \pm 0.5^{\circ} \mathrm{C}$, $65 \pm 5 \%$ relative humidity and 16L:8D photoperiod. Sequences of a $762 \mathrm{bp}$ region of the mitochondrial COI gene for these two populations are identical (GenBank accession numbers AY264343 and EU488723). This region has shown its utility in distinguishing cryptic species in the genus Encarsia (Monti et al., 2005), therefore we consider the two populations to be conspecific.

Molecular analysis to detect the bacterial infection Previously it has been shown that the only inherited bacterial symbiont in Californian E. hispida is Cardinium (Zchori-Fein et al., 2004). Here we analyzed the Italian population. The presence of the bacterial symbionts associated with thelytokous reproduction in arthropods, including Cardinium, Wolbachia and Rickettsia (Huigens and Stouthamer, 2003; Hagimori et al., 2006; Hunter and Zchori-Fein, 2006), was checked in 20 Italian females by PCR using the following sets of primers: CLOf and CLOr1 (Weeks et al., 2003), and ChF and ChR (ZchoriFein and Perlman, 2004) for Cardinium 16S rDNA; ftsZf1 and ftsZr1 (Werren et al., 1995) for Wolbachia ftsZ cellcycle gene; Rb-F and Rb-R (Gottlieb et al., 2006) for Rickettsia $16 \mathrm{~S}$ rDNA.

To verify the possible presence of any other symbiont, the bacterial 16S rDNA was amplified from single E. hispida using the universal primers $27 \mathrm{~F}$ and $1513 \mathrm{R}$ (Weisburg et al., 1991), cloned and sequenced. A highfidelity AccuTaq LA DNA polymerase (Sigma-Aldrich,
Saint Louis, MO, USA) was used in PCR protocols following the manufacturer's instructions. Samples that yielded amplicons of the expected size $(\sim 1500 \mathrm{bp})$ were cloned by using p-GEMT Easy Vector System (Promega, Madison, WI, USA). Five females were analyzed, and 3-6 different clones from each wasp were sequenced, using the ABI Prism Big Dye terminator Cycle Sequencing Kit and the ABI Prism 310 Genetic Analyzer (Applied Biosystems, Foster City, CA, USA) sequencer according to the manufacturer's protocols. To obtain overlapping sequences and to resolve ambiguities, both DNA strands were sequenced. Sequences were assembled using SeqMan in the Lasergene software package (Dnastar, Madison, WI, USA). Alignments were carried out with the ClustalW method of MegAlign in the same package. The sequences were compared to sequences in GenBank using BLAST searches.

\section{Induction of male progeny by antibiotic treatment}

Females were treated with antibiotics to produce male larvae for karyological analysis and male adults for DNA measurement by flow cytometry. Because it is not feasible to sex the larvae, a preliminary experiment was performed to select a treatment inducing $100 \%$ male progeny. Newly emerged individual adult females of the Italian E. hispida were fed with tetracycline in honey $\left(50 \mathrm{mg} \mathrm{ml}^{-1}\right)$ for $24 \mathrm{~h}$ in a glass vial and then allowed to oviposit for $48 \mathrm{~h}$ on a bean leaf disk infested with 50 greenhouse whitefly nymphs. The leaf disks were $35 \mathrm{~mm}$ diameter and laid onto a 4-5 mm thick layer of $1 \%$ water agar in a $35 \mathrm{~mm}$ ventilated Petri dish. At 8-10 days after the wasps were removed, parasitized pupal cases containing the parasitoid pupae were singly isolated in vials, and the emerged adults were sexed. Experimental conditions were $25 \pm 0.5^{\circ} \mathrm{C}, 65 \pm 5 \%$ relative humidity and 16L:8D photoperiod. PCR assays with the Cardiniumspecific primers were performed on 20 treated adult females immediately after the antibiotic treatment and 20 newly emerged adult males, each one chosen from the progeny of 20 different treated females. To obtain allmale progenies from Californian E. hispida, adult females were fed with rifampicin as described by Zchori-Fein et al. (2004).

\section{Effect of tetracycline on fertility and longevity of treated E. hispida}

Fertility was measured as number of adult offspring produced by each female ovipositing for $48 \mathrm{~h}$ as described above. Tetracycline-treated females $(n=19)$ were compared to newly emerged untreated females fed with honey only for $24 \mathrm{~h}(n=14)$. To test for antibiotic toxicity, we compared the longevity of tetracyclinetreated females $(n=49)$ to that of untreated females $(n=46)$. Longevity was measured in the absence of hosts. Newly emerged single females, after the initial $24 \mathrm{~h}$ treatment, were kept in a glass vial and fed with honey (fresh honey was supplied every 5 days) until death (females were checked daily).

\section{Determination of the karyotype}

Analysis of the chromosome sets was performed on both female and male individuals. Metaphase chromosomes were obtained from samples of third instar larvae. Each sample consisted of all of the progeny of single females. 
The progeny of 50 tetracycline-treated and 20 infected females of the Italian population, and of 10 rifampicintreated and 10 infected females of the Californian population was analyzed. Larvae were extracted from parasitized whitefly puparia in a drop of saline and subjected to the scraping plus air-drying method reported by Baldanza et al. (1993) with the following modifications. The larval progeny of each female was dissected (each larva was nicked between head and thorax) in $0.5 \mathrm{ml}$ colchicine $0.1 \%$ in Shen solution $(0.9 \mathrm{~g}$ $\mathrm{NaCl}, 0.042 \mathrm{~g} \mathrm{KCl}, 0.025 \mathrm{~g} \mathrm{CaCl}_{2}$ in $100 \mathrm{ml}$ distilled water) and incubated at room temperature for $1 \mathrm{~h}$. After incubation, the colchicine solution containing the dissected larvae was transferred in a $1.5 \mathrm{ml}$ tube and centrifuged at 1300 r.p.m. for $10 \mathrm{~min}$. The supernatant was removed, $0.5 \mathrm{ml}$ of hypotonic solution (sodium citrate $0.5 \%$ ) was added and after $20 \mathrm{~min}$ the tube was centrifuged at 1300 r.p.m. again for $10 \mathrm{~min}$. The supernatant was removed, and $0.5 \mathrm{ml}$ of fixative (glacial acetic acid/methanol 3:1) was added. After $1 \mathrm{~h}$ at $4{ }^{\circ} \mathrm{C}$ the tissues were broken up by sucking and pushing them repeatedly with a pipettor equipped with a $0.2 \mathrm{ml}$ tip. The samples were pelleted by centrifugation at 1300 r.p.m. for $10 \mathrm{~min}$. The supernatant was removed, $0.5 \mathrm{ml}$ of fixative was added and a new centrifugation at 1300 r.p.m. for $10 \mathrm{~min}$ was performed. After the supernatant was removed, the pellet was resuspended in volumes of fixative necessary to spread the pellet on slides $(0.01 \mathrm{ml}$ fixative per three larvae processed). Eventually, samples were dropped on slides $(0.01 \mathrm{ml}$ per slide), air-dried and stained in Giemsa (5\% in phosphate buffer, $\mathrm{pH} 6.8$ ).

\section{Measurement of the nuclear DNA content}

Flow cytometry was performed on samples of five Californian E. hispida combined with one Drosophila melanogaster adult as an internal standard. Male and female adult wasps were analyzed separately, and, for each sex three replicates were performed. To assess the ploidy level, quantification of DNA content was carried out from nuclei derived from head cells, mainly the brain tissue. Nervous tissue in Hymenoptera reflects the true ploidy level of the insect (Aron et al., 2005). Heads were dissected from freshly killed insects and macerated in a drop of Galbraith buffer (Galbraith et al., 1983) with a razor blade to free nuclei. As a size standard, half of a head of $D$. melanogaster was added to each sample. The volume of buffer was adjusted to $1 \mathrm{ml}$, and the samples were filtered through a $20 \mu \mathrm{m}$ mesh nylon filter and stained with $75 \mu \mathrm{l}$ propidium iodide $\left(1 \mathrm{mg} \mathrm{ml}^{-1}\right)$ for $1-2 \mathrm{~h}$ while kept on ice. The mean fluorescence of stained nuclei in each sample was determined by a Becton Dickinson FACScan flow cytometer, with a $488 \mathrm{~nm}$ Argon ion laser, after exclusion of cellular debris and nuclear doublets. Data were analyzed by the software CellQuest.

\section{Results}

Like rifampicin-fed Californian E. hispida (Zchori-Fein et al., 2004), tetracycline-fed females of the Italian population produced all-male adult progeny, whereas naturally infected females produced only daughters. In addition, the number of viable adult offspring produced by tetracycline-treated Italian females was significantly lower (mean of adult sons \pm s.d. $4 \pm 2.18$, $n=19$ ) than that produced by untreated females (mean of adult daughters \pm s.d. $13.93 \pm 2.61, n=14$ ) (analysis of variance (ANOVA) test, $\mathrm{F}_{1,31}=140.81, P=0$ ). No negative effect of tetracycline on longevity of treated females was found. Longevity did not differ significantly (ANOVA test, $F_{1,93}=0.58, P=0.45$ ) between treated (mean \pm s.d. $37.02 \pm 14.27$ days, $n=49$ ) and untreated females (mean \pm s.d. $34.83 \pm 13.77$ days, $n=46$ ). A reduction of the number of viable offspring produced by treated females was observed also for the Californian population (Zchori-Fein et al., 2004).

PCR assays on untreated females of the Italian E. hispida revealed that all females were positive for Cardinium but not for Wolbachia and Rickettsia. Forty-five percent of tetracycline-treated females remained infected immediately after the antibiotic treatment; in spite of this, the progeny of treated females was always male and Cardinium was never detected in any male offspring. Similar results were obtained for Californian E. hispida, with the difference that the uninfected males were produced by rifampicin-treated females and PCR failed to detect Cardinium in these females (Zchori-Fein et al., 2004).

Amplifications of the bacterial 16S rDNA extracted from Italian E. hispida produced a fragment of $\sim 1500 \mathrm{bp}$. After deletion of primers, aligned sequences from 22 out of 24 clones showed a high degree of similarity (average of $99.81 \%$ ) and had a 99.6-100\% similarity with the sequence of Cardinium found in the Californian population (GenBank accession number AY331187; Zchori-Fein et al., 2004). Sequences were deposited in GenBank (accession numbers DQ854692-DQ854713). The consensus sequence generated from these clones showed $100 \%$ similarity with the sequence of Cardinium found in the Californian E. hispida. The sequences of the two remaining clones were only found once; BLAST results from GenBank indicate that one was $99 \%$ similar to a Methylobacterium sp. (GenBank accession number AM237344), whereas the other did not show any significant matche. No evidence exists for involvement of these bacteria in any reproductive manipulation and we consider them to be environmental contaminants. We conclude that Cardinium is the only intracellular symbiont of Italian E. hispida, as it is in the Californian population.

The analysis of the male karyotype showed 10 chromosomes in the metaphase plates examined

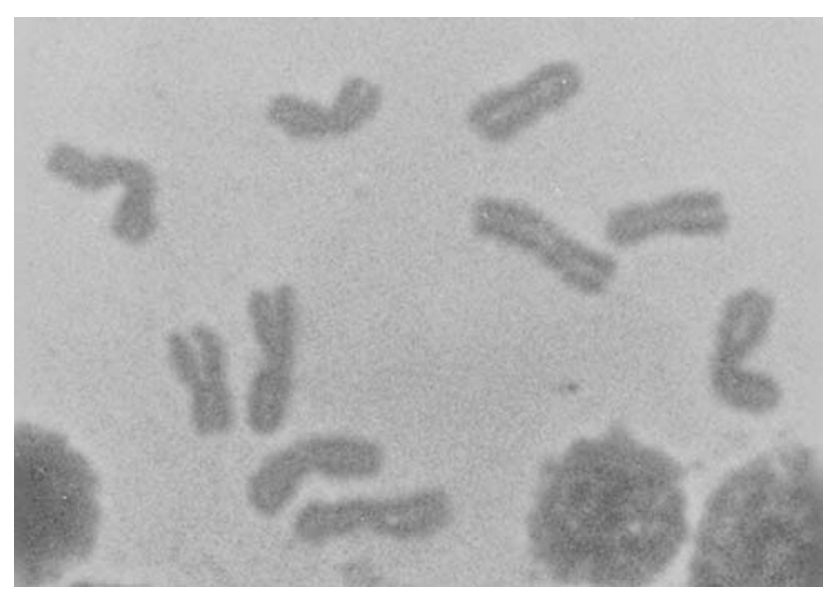

Figure 1 Karyotype of a male of E. hispida $(2 n=10)$. 
( $n>100)$ (Figure 1). Observations of female metaphase preparations $(n>100)$ were consistent with a previous study (Baldanza et al., 1999), which showed, through chromosome banding techniques, that E. hispida females are diploid with karyotype $2 n=10$. The flow cytometry analysis ruled out the possibility that male tissue was a mosaic of haploid and diploid cells; we observed no notable differences between the nuclear DNA content of females and males (Figure 2) and thus we conclude that both sexes are entirely diploid.

\section{Discussion}

We found that Cardinium is the causal agent of asexual reproduction in an Italian population of E. hispida, as it is in a Californian population. We also found that in both populations, antibiotic-treated females produce only uninfected male progeny. These males have the same ploidy level as females and are diploid. The results suggest that Cardinium manipulate the reproduction of E. hispida by feminizing unfertilized diploid male eggs, which then develop into functional adult females.

Second, we found that tetracycline treatment of E. hispida has a negative impact on offspring production. This effect is not antibiotic specific, as a reduction in
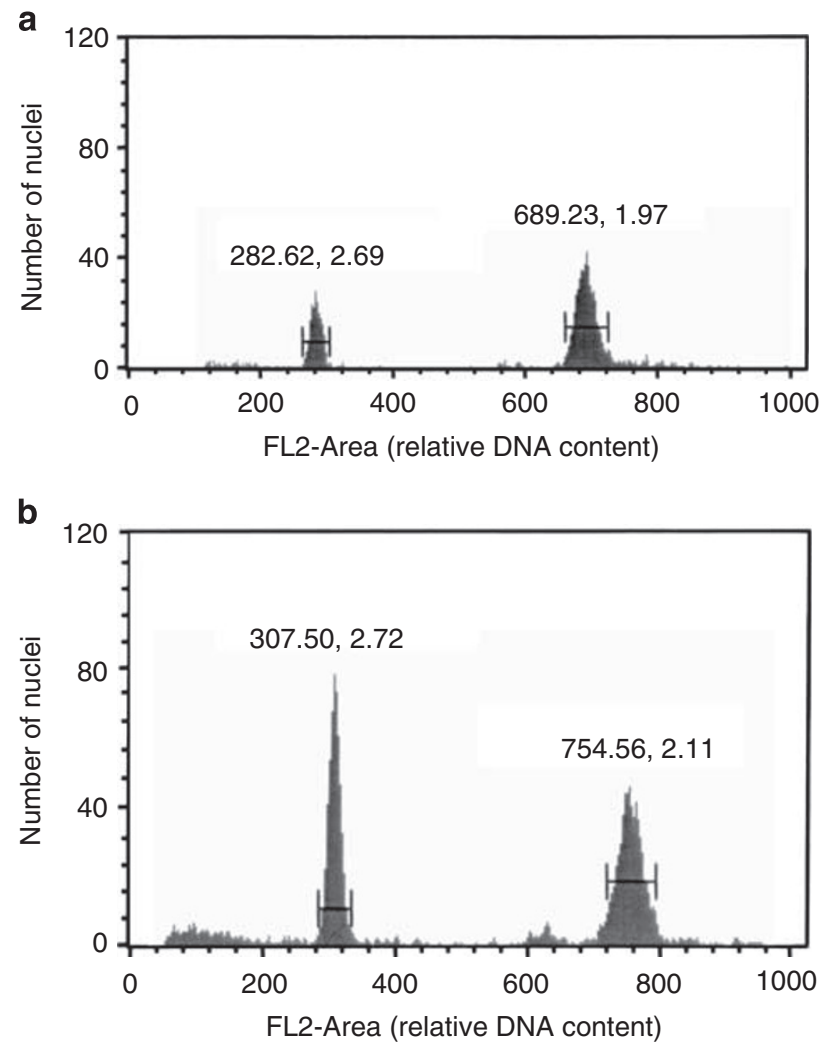

Figure 2 Flow cytometric DNA histograms from a sample of (a) female and (b) male wasps. The number of nuclei with different levels of fluorescence (relative nuclear DNA content) is shown; the mean value of fluorescence and the coefficient of variation are given above the peak. Two major peaks of nuclei can be observed: on the left is the internal standard D. melanogaster, on the right is E. hispida. Females and males show similar nuclear DNA content (2.44- and 2.45-fold the standard, respectively); no peak for haploid nuclei occurs in male wasps. Similar results were obtained from all replicates of the experiment (data not shown). fertility was also observed when rifampicin was used (Zchori-Fein et al., 2004). We can suggest three nonexclusive hypotheses for lowered fertility: antibiotic toxicity, developmental instability or higher mortality of developing male progeny, and a fitness benefit to the presence of Cardinium that is lost after antibiotic curing. Of these, we think antibiotic toxicity may be the least likely hypothesis, although negative effect of antibiotics have been reported in the Wolbachia-infected E. formosa (Stouthamer and Mak, 2002). Our results show that the antibiotic treatment has no negative effects on the longevity of treated E. hispida. In addition, in three separate studies on Encarsia species infected by Cardinium, antibiotics did not influence the number of eggs laid (Kenyon and Hunter, 2007) or the fertility of cured females (Hunter et al., 2003; Perlman et al., 2006). Finally, the fitness of Cardinium-infected asexual mites has not been negatively influenced by antibiotic treatment (Chigira and Miura, 2005). It is perhaps more plausible to imagine that diploid males may suffer higher developmental mortality, or if immature intersexes occur, they may not survive to adulthood. Finally, it is possible that Cardinium is necessary for normal levels of fertility of E. hispida. Cardinium could be involved in oogenesis as well as in embryogenesis and larval development. For instance, Cardinium infection is associated with an increase of fecundity in a mite host (Weeks and Stouthamer, 2004). In other examples, the reproductive manipulator Wolbachia is necessary for oogenesis in a parasitic wasp (Dedeine et al., 2001) and for normal development of eggs in the vine weevil (Son et al., 2008).

\section{Symbiont-mediated transitions between thelytoky and feminization, haplodiploidy and diploidy}

Several microorganisms, including microsporidia and bacteria, are feminizers in diploid arthropods (Rigaud, 1997). Wolbachia is a feminizer in two species with female heterogamety (Rigaud, 1997; Hiroki et al., 2002), and in a species with an XX/X0 sex determination system (Negri et al., 2006). Within haplodiploid arthropods, so far, feminization has been reported only for Cardinium in the asexual mite Brevipalpus where Cardinium feminizes unfertilized haploid eggs (Weeks et al., 2001; Chigira and Miura, 2005). This mechanism of feminization in Brevipalpus differs from that described here in E. hispida, where unusual diploid males are converted to females.

In the Hymenoptera, thelytoky (asexual reproduction determining the development of diploid female from unfertilized eggs) is common in the superfamily Chalcidoidea (van Wilgenburg et al., 2006), and strongly associated with infections of Wolbachia (Huigens and Stouthamer, 2003) or Cardinium (Hunter and Zchori-Fein, 2006). In Wolbachia-infected parthenogenetic wasps the bacteria are responsible for diploidy restoration in unfertilized eggs (Stouthamer and Kazmer, 1994; Gottlieb et al., 2002; Pannebaker et al., 2004). Recently, a Rickettsia has also been found to cause diploidy restoration in a thelytokous chalcidoid species (Adachi-Hagimori et al., 2008). In E. hispida, the observation that antibiotic treatment causes the production of diploid sons suggests either a very early role, or no role for Cardinium in diploidy restoration of unfertilized eggs. Because asexual reproduction in the genus Encarsia is almost exclusively associated with Cardinium infection (Zchori-Fein et al., 
2001), it is highly likely that Cardinium is ultimately responsible for the generation of diploid males in E. hispida. What cannot currently be determined is whether that role was historical, such that diploidy is now fixed in E. hispida and controlled by the host, or whether in development, diploidy restoration is determined upstream of feminization, such that antibiotic treatment prevents the latter, but not the former. Bacterial products formed within the infected mother could be sufficient for diploidy restoration, but live bacteria in the eggs may be necessary to feminize. Similarly, Arakaki et al. (2000) suggested that bacterial products, not live Wolbachia in the eggs, are necessary for diploidy restoration in the thelytokous parasitoid Telenomus nawai. Determining whether Cardinium is evolutionarily or currently (during development) responsible for diploidy restoration would allow us to more precisely name the reproductive phenotype as parthenogenesis induction (haploid males convert to diploid females) or feminization in the strict sense (diploid males develop as functional females). This predicament also highlights the close relationship between these two phenotypes of reproductive manipulation; although they are often treated as dichotomous, they may grade into each other.

These results are, to the best of our knowledge, the first report of diploid males associated with symbiont infection in the Chalcidoidea, where the greatest number of records of parthenogenesis induction by symbionts occurs. In addition, diploid males have never been found in the genus Encarsia where the occurrence of haploid males is the rule in all sexual species studied so far (Hunter et al., 1993; Baldanza et al., 1999). Aside from our findings in E. hispida, only two examples of diploid males are known in the hymenopteran groups where the genetic mechanism of single-locus complementary sex determination (sl-CSD) is absent (Stille and Darving, 1980; Dobson and Tanouye, 1998). In sl-CSD groups, diploid males arise from inbreeding due to homozygosity at the sex locus; heterozygous and hemizygous individuals are females and males, respectively (van Wilgenburg et al., 2006). In the non-CSD bisexual Nasonia vitripennis (Chalcidoidea) diploid males may be produced following mutagenesis (Whiting, 1960; Trent et al., 2006). In the other example, diploid males have been recorded in the thelytokous gall wasp Diplolepis rosae (Cynipoidea) (Stille and Darving, 1980) where homozygous parthenogenesis is associated with Wolbachia infection (van Meer et al., 1999). To our knowledge, however, in PI-Wolbachia-infected wasps, there are no studies of antibiotic curing and diploidy restoration that have performed cytogenetic analyses to reveal the ploidy level of the males produced by cured females. The widely accepted explanation for Wolbachia-induced parthenogenesis is that Wolbachia influences only ploidy level (Huigens and Stouthamer, 2003), and female development of the host then follows without bacterial influence on the sex determination system. It is not yet clear whether this explanation is correct for PI-Wolbachiainfected wasps, but our data show it to be false for PICardinium. Although diploidy restoration is likely a necessary condition, it is not sufficient to elicit female development in E. hispida. Cardinium is required to feminize diploid (male) embryos and must interact with elements of the host sex determination system. This contrasts with the recent discovery of a PI-Rickettsia able to induce female development by only diploidization of unfertilized eggs in the parasitoid Neochrysocharis formosa; in this system antibiotic treatment of infected females causes the production of haploid males (Adachi-Hagimori et al., 2008).

In Hymenoptera without sl-CSD, the mechanism of sex determination is not well understood. For Nasonia, a model based on genomic imprinting, in which female development occurs when paternally inherited genes are present during zygotic development, has been proposed (Dobson and Tanouye, 1998; Beukeboom et al., 2007). One of the difficulties with this model, however, has been its inability to explain female development in impaternate thelytokous wasps without claiming feminization has been taken over by the bacterium. Although models of sex determination developed for Nasonia may not apply to all the Chalcidoidea, it is interesting to note that genomic imprinting is consistent with the occurrence of diploid males in E. hispida because the progeny inherits only maternally derived genes and Cardinium controls sex determination.

Finally, our finding of feminizing Cardinium and diploid males in E. hispida suggests a possible route for the collapse of haplodiploidy into a diplodiploid genetic system. Hosts may contribute to or take over the process of asexual diploidy restoration from symbionts if this reduces mortality of parthenogenetic daughters. Reversion to diplodiploidy from haplodiploidy is quite rare, but in one of two examples of scale insects highlighted by Normark (2004), symbionts appear to have a function. Although relatives are haplodiploid, Buchner (1965) noted that female embryos in the family Stictococcidae are diploid and infected with a bacterium, whereas males are also diploid, but free of bacteria. The interaction of reproductive manipulators with host sex determination systems may lead to the diversification of arthropod sex determination (Rigaud, 1997; Charlat et al., 2003), and also genetic systems more generally.

\section{Acknowledgements}

We thank G Tulgetske for her help with the flow cytometry. This work was supported by a CNR Short Term Mobility Fellowship (year 2005) and a CNR grant no. AG.P01.013 to MG, an NSF-FIBR grant no. DEB0328363 to RS and an NSF grant no. DEB-0542961 to MSH.

\section{References}

Adachi-Hagimori T, Miura K, Stouthamer R (2008). A new cytogenetic mechanism for bacterial endosymbiont-induced parthenogenesis in Hymenoptera. Proc $R$ Soc $B$ 275: 2667-2673.

Arakaki N, Noda H, Yamagishi K (2000). Wolbachia-induced parthenogenesis in the egg parasitoid Telenomus nawai. Entomol Exp Appl 96: 177-184.

Aron S, de Menten L, Van Bockstaele DR, Blank SM, Roisin Y (2005). When Hymenopteran males reinvented diploidy. Curr Biol 15: 824-827.

Baldanza F, Gaudio L, Viggiani G (1999). Cytotaxonomic studies of Encarsia Förster (Hymenoptera: Aphelinidae). Bull Entomol Res 89: 209-215.

Baldanza F, Odierna G, Viggiani G (1993). A new method for studying chromosomes of parasitic Hymenoptera, used on Encarsia berlesei (Howard) (Hymenoptera: Aphelinidae). Boll Lab Ent agr Filippo Silvestri 48: 29-34. 
Beukeboom LW, Kamping A, van de Zande L (2007). Sex determination in the haplodiploid wasp Nasonia vitripennis (Hymenoptera: Chalcidoidea): a critical consideration of models and evidence. Semin Cell Dev Biol 18: 371-378.

Buchner P (1965). Endosymbiosis of Animals with Plant Microorganisms. Wiley: New York.

Caubet Y, Hatcher MJ, Mocquard J-P, Rigaud T (2000). Genetic conflict and changes in heterogametic mechanisms of sex determination. I Evol Biol 13: 766-777.

Charlat S, Hurst GDD, Mercot H (2003). Evolutionary consequences of Wolbachia infections. Trends Genet 19: 217-223.

Chigira A, Miura K (2005). Detection of Candidatus Cardinium bacteria from the haploid host Brevipalpus californicus (Acari: Tenuipalpidae) and effect on the host. Exp Appl Acarol 37: 107-116.

Dedeine F, Vavre F, Fleury F, Loppin B, Hochberg ME, Boulétreau M (2001). Removing symbiotic Wolbachia bacteria specifically inhibits oogenesis in a parasitic wasp. Proc Natl Acad Sci USA 98: 6247-6252.

Dobson SL, Tanouye MA (1998). Evidence for a genomic imprinting sex determination mechanism in Nasonia vitripennis (Hymenoptera: Chalcidoidea). Genetics 149: 233-242.

Duron O, Hurst GDD, Hornett EA, Josling JA, Engelstäder J (2008). High incidence of the maternally inherited bacterium Cardinium in spiders. Mol Ecol 17: 1427-1437.

Galbraith DW, Harkins KR, Maddox JM, Ayres NM, Sharma DP, Firoozabady E (1983). Rapid flow cytometric analysis of the cell cycle in intact plant tissues. Science 220: 1049-1051.

Giorgini M (2001). Induction of males in thelytokous populations of Encarsia meritoria Gahan and Encarsia protransvena Viggiani (Hymenoptera: Aphelinidae): a systematic tool. Biocontrol 46: 427-438.

Gotoh T, Noda H, Ito S (2007). Cardinium symbionts cause cytoplasmic incompatibility in spider mites. Heredity 98: $13-20$

Gottlieb Y, Ghanim M, Chiel E, Gerling D, Portnoy V, Steinberg $S$ et al (2006). Identification and localization of a Rickettsia sp. in Bemisia tabaci (Homoptera: Aleyrodidae). Appl Environ Microbiol 72: 3646-3652.

Gottlieb Y, Zchori-Fein E, Werren JH, Karr TL (2002). Diploidy restoration in Wolbachia-infected Muscidifurax uniraptor (Hymenoptera: Pteromalidae). J Invertebr Pathol 81: 166-174.

Groot TVM, Breeuwer JAJ (2006). Cardinium symbionts induce haploid thelytoky in most clones of three closely related Brevipalpus species. Exp Appl Acarol 39: 257-271.

Hagimori T, Abe Y, Date Y, Miura K (2006). The first finding of a Rickettsia bacterium associated with parthenogenesis induction among insects. Curr Microbiol 52: 97-101.

Hamilton WD (1993). Inbreeding in Egypt and in this book: a childish perspective. In: Thornhill NW (ed). The Natural History of Inbreeding and Outbreeding: Theoretical and Empirical Perspectives. University of Chicago Press: Chicago. pp 429-450.

Heraty JM, Woolley JB (2002). Encarsia Species of the World: A Searchable Database. http://chalcidoids.tamu.edu/ENCARSIA/encarsia.htm.

Hiroki M, Kato Y, Kamito T, Miura K (2002). Feminization of genetic males by a symbiotic bacterium in a butterfly, Eurema hecabe (Lepidoptera: Pieridae). Naturwissenschaften 89: 167-170.

Huigens ME, Stouthamer R (2003). Parthenogenesis associated with Wolbachia. In: Bourtzis K, Miller TA (eds). Insect Symbiosis. CRC Press: Boca Raton, FL. pp 247-266.

Hunter MS (1999). The influence of parthenogenesis-inducing Wolbachia on the oviposition behaviour and sex-specific developmental requirements of autoparasitoid wasps. J Evol Biol 12: 735-741.

Hunter MS, Nur U, Werren JH (1993). Origin of males by genome loss in an autoparasitoid wasp. Heredity 70: 162-171.
Hunter MS, Perlman SJ, Kelly SE (2003). A bacterial symbiont in the Bacteroidetes induces cytoplasmic incompatibility in the parasitoid wasp Encarsia pergandiella. Proc $R$ Soc Lond B 270: 2185-2190.

Hunter MS, Woolley JB (2001). Evolution and behavioural ecology of heteronomous aphelinid parasitoids. Annu Rev Entomol 46: 251-290.

Hunter MS, Zchori-Fein E (2006). Inherited Bacteroidetes symbionts in arthropods. In: Bourtzis K, Miller TA (eds). Insect Symbiosis. CRC Press: Boca Raton, FL. vol 2, pp 39-56.

Kenyon SG, Hunter MS (2007). Manipulation of oviposition choice of the parasitoid wasp, Encarsia pergandiella, by the endosymbiotic bacterium Cardinium. I Evol Biol 20: 707-716.

Matalon Y, Katzir N, Gottlieb Y, Portnoy V, Zchori-Fein E (2007). Cardinium in Plagiomerus diaspidis (Hymenoptera: Encyrtidae). I Invertebr Pathol 96: 106-108.

Monti MM, Nappo AG, Giorgini M (2005). Molecular characterization of closely related species in the parasitic genus Encarsia (Hymenoptera: Aphelinidae) based on the mitochondrial cytochrome oxidase subunit I gene. Bull Entomol Res 95: 401-408.

Negri I, Pellecchia M, Mazzoglio PJ, Patetta A, Alma A (2006). Feminizing Wolbachia in Zyginida pullula (Insecta, Hemiptera), a leafhopper with an XX/X0 sex-determination system. Proc $R$ Soc Lond B 273: 2409-2416.

Normark BB (2004). Haplodiploidy as an outcome of coevolution between male-killing cytoplasmic elements and their hosts. Evolution 58: 790-798.

Pannebaker BA, Pijnacker LP, Zwaan BJ, Beukeboom LW (2004). Cytology of Wolbachia-induced parthenogenesis in Leptopilina clavipes (Hymenoptera: Figitidae). Genome 47: 299-303.

Perlman SJ, Kelly SE, Zchori-Fein E, Hunter MS (2006). Cytoplasmic incompatibility and multiple symbiont infection in the ash whitefly parasitoid, Encarsia inaron. Biol Control 54: 961-968.

Polaszek A, Manzari S, Quicke DLJ (2004). Morphological and molecular taxonomic analysis of the Encarsia meritoria species-complex (Hymenoptera, Aphelinidae), parasitoids of whiteflies (Hemiptera, Aleyrodidae) of economic importance. Zool Scripta 33: 403-421.

Provencher LM, Morse GE, Weeks AR, Normark BB (2005). Parthenogenesis in the Aspidiotus nerii complex (Hemiptera: Diaspididae): a single origin of a worldwide, polyphagous lineage associated with Cardinium bacteria. Ann Entomol Soc Am 98: 629-635.

Rigaud T (1997). Inherited microorganisms and sex determination of arthropod hosts. In: O'Neill S, Hoffmann AA, Werren $\mathrm{JH}$ (eds). Influential Passengers: Inherited Microorganism and Arthropod Reproduction. Oxford University Press: New York. pp 81-101.

Son Y, Luckhart S, Zang X, Lieber MJ, Lewis EE (2008). Effects and implications of antibiotic treatment on Wolbachiainfected vine weevil. Agr Forest Entomol 10: 147-155.

Stille B, Darving L (1980). Meiosis and reproductive strategy in the parthenogenetic gall wasp Diplolepis rosae (L. Hymenoptera: Cynipidae). Hereditas 92: 353-362.

Stouthamer R, Kazmer DJ (1994). Cytogenetics of microbeassociated parthenogenesis and its consequences for gene flow in Trichogramma wasps. Heredity 73: 317-327.

Stouthamer R, Mak F (2002). Influence of antibiotics on the offspring production of the Wolbachia-infected parthenogenetic parasitoid Encarsia formosa. I Invertebr Pathol 80: 41-45.

Trent C, Crosby C, Ravey J (2006). Additional evidence for the genomic imprinting model of sex determination in the haplodiploid wasp Nasonia vitripennis: isolation of biparental diploid males after X-ray mutagenesis. Heredity 96: 368-376.

van Meer MMM, Witteweldt J, Stouthamer R (1999). Phylogeny of the arthropod endosymbionts Wolbachia based on the wsp gene. Insect Mol Biol 8: 399-408. 
van Wilgenburg E, Driessen G, Beukeboom LW (2006). Single locus complementary sex determination in Hymenoptera: an 'unintelligent' design? Front Zool 3: 1. doi: 10.1186/1742-9994-3-1.

Weeks AR, Marec F, Breeuwer JAJ (2001). A mite species that consist entirely of haploid females. Science 292: 2479-2482.

Weeks AR, Velten R, Stouthamer R (2003). Incidence of a sexratio-distorting endosymbiotic bacterium among arthropods. Proc $R$ Soc Lond B 270: 1857-1865.

Weeks AR, Stouthamer R (2004). Increased fecundity associated with infection by a Cytophaga-like intracellular bacterium in the predatory mite, Metaseiulus occidentalis. Proc $R$ Soc Lond $B$ (Suppl) 271: S193-S195.

Weisburg WGS, Barns SM, Pelletier DA, Lane DL (1991). 16S ribosomial DNA amplification for phylogenetic study. J Bacteriol 173: 697-703.

Werren JH, Beukeboom LW (1998). Sex determination, sex ratios and genetic conflict. Annu Rev Ecol Syst 29: 233-261.
Werren JH, Zhang W, Guo LR (1995). Evolution and phylogeny of Wolbachia: reproductive parasites of arthropods. Proc $R$ Soc Lond B 261: 55-63.

Werren JH, O'Neill S (1997). The evolution of heritable symbionts. In: O'Neill S, Hoffmann AA, Werren JH (eds). Influential Passengers: Inherited Microorganism and Arthropod Reproduction. Oxford University Press: New York. pp 1-41.

Whiting PW (1960). Polyploidy in Mormoniella. Genetics 45: 949-970.

Zchori-Fein E, Gottlieb Y, Kelly SE, Brown JK, Wilson JM, Karr TL et al (2001). A newly discovered bacterium associated with parthenogenesis and a change in host selection behavior in parasitoid wasps. Proc Natl Acad Sci USA 98: 12555-12560.

Zchori-Fein E, Perlman SJ (2004). Distribution of the bacterial symbiont Cardinium in arthropods. Mol Ecol 13: 2009-2016.

Zchori-Fein E, Perlman SJ, Kelly SE, Katzir N, Hunter MS (2004). Characterization of a Bacteroidetes symbiont in Encarsia wasp (Hymenoptera: Aphelinidae): proposal of Candidatus Cardinium hertigii. Int J Syst Evol Microbiol 54: 961-968. 